We would like to express our thanks to Dr. J. Ward Regan, medical consultant to the Pharmaceutical Division of Pennwait Corporation (U.S.A.) for supply of metolazone, and also to the patients who so willingly took part in this trial.

\section{References}

Allison, M. E. M., and Kennedy, A. C. (1971). Clinical Science, 41, 171. Belair, E. J., Kaiser, F., and Van Denburg, B. (1969). Archives Internationales de Pharmacodynamie et de Thérapie, 177, 71.

Dettli, L., and Spring, P. (1966). Annals of the New York Academy of Sciences, $139,471$.

Hare, R. S. (1950). Proceedings of the Society for Experimental Biology and Medicine, 74, 148 .

Lancet, 1971, 2, 803.
Laragh, J. H., Cannon, P. J., Stason, W. B., and Heinemann, H. O. (1966). Annals of the New York Academy of Sciences, 139, 453.

McKenzie, I. F., Fairley, K. F., and Baird, C. W. (1966). Medical fournal of Australia, 1, 879.

Maher, J. F., and Schreiner, G. E. (1965). Annals of Internal Medicine, 62 15.

Materson, B. J., and Barkin, J. S. (1970). Clinical Research, 18, 64.

Michelis, M. F., De Rubertis, F., and Beck, N. P. (1970). Fournal of Clinical Pharmacology and Therapeutics, 11, 821.

Muth, R. G. (1966). Fournal of the American Medical Association, 195, 1066. Muth, R. G. (1968). Annals of Internal Medicine, 69, 249

Reubi, F. C., and Cottier, P. T. (1961). Circulation, 23, 200.

Schoonees, R., Mostert, J. W., Moore, R. H., Stetson, J. B., and Murphy, G. P. (1971). New York State Fournal of Medicine, 71, 566

Silverberg, D. S., and Kjellstrand, C. M. (1968). Acta Medica Scandinarica, 184,473 .

Steinmuller, S., and Puschett, J. B. (1971). American College of Physicians, March, 30.

Steinmuller, S., and Puschett, J. B. (1972). Kidney International, 1, 169.

\title{
Effect of Posture on Glucose Tolerance after Gastric Surgery
}

\author{
C. D. HOLDSWORTH, I. HULME-MOIR, C. THIRUMALAI
}

British Medical fournal, 1972, 4, 198-200

\begin{abstract}
Summary
Oral glucose tolerance after either partial gastrectomy or vagotomy and pyloroplasty for duodenal ulcer was markedly affected by posture. Peak blood glucoses and the degree of reactive hypoglycaemia were greater in the erect than in the supine position. This is probably due to positional changes in gastric emptying, and our findings support the view that after gastric surgery alteration in gastric emptying rate is the main factor responsible for the change in oral glucose tolerance.
\end{abstract}

\section{Introduction}

Glucose tolerance is often abnormal after gastric resection, with a high peak value and a tendency to reactive hypoglycaemia. We have previously presented evidence that this reactive hypoglycaemia is due largely to the altered pattern of gastric emptying rather than to hypersecretion of insulin (Holdsworth et al., 1969). Gastric emptying of a "balanced" fluid meal has been shown to vary greatly with posture after vagotomy and a drainage procedure (McKelvey et al., 1969), and this is also true for $20 \mathrm{~g} / 100 \mathrm{ml}$ of glucose solution after either vagotomy and pyloroplasty or a Polya partial gastrectomy (I. HulmeMoir and C. D. Holdsworth, unpublished observations). We have, therefore, studied the effect of posture on glucose tolerance in patients with gastric and duodenal ulcer before and after surgery.

\section{Patients and Methods}

The subjects studied were a consecutive series of patients referred to a surgical unit with an established diagnosis of benign gastric or duodenal ulcer. Preoperative studies were carried out a few days before surgery. Postoperative studies were carried out several weeks after surgery. Oral glucose tolerance tests were performed after an overnight fast while otherwise

Royal Infirmary, Sheffield

C. D. HOLDSWORTH, M.D., M.R.C.P., Consultant Physician

St. Bartholomew's Hospital, London E.C.1

I. HULME-MOIR, F.R.C.S., Research Fellow in Surgery

C. THIRUMALAI, B.SC., Research Assistant in Medicine on an unrestricted carbohydrate intake using $50 \mathrm{~g}$ of glucose dissolved in $250 \mathrm{ml}$ of orange-flavoured water, and sampling venous blood from an antecubital vein. During supine studies the patient lay on a horizontal table, and during erect studies the patient was seated strictly upright, maintained in this position by a light harness attached to the vertical back of a specially constructed chair.

Blood glucose was measured by a reducing method on a Technicon AutoAnalyzer. Plasma levels of immunoreactive insulin were determined by radioimmunoassay, using dextrancoated charcoal to separate the bound and free fractions (Herbert et al., 1965). The significance of differences in blood glucose and plasma insulin was assessed by Student's $t$ test for unpaired data, as it was not possible to study all patients in the two positions. Statistical analysis of data was carried out only for "peak levels," which are the highest blood glucose or plasma insulin levels recorded during a test, and for the degree of "reactive hypoglycaemia." By reactive hypoglycaemia we mean the maximum fall in blood glucose below fasting levels observed late in the test, between 90 and 150 minutes after ingestion of the glucose meal.

\section{Results}

\section{DUODENAL ULCER}

Preoperative.-Posture had no significant effect on the glucose tolerance (Fig. 1). The peak blood glucose level was only slightly higher during the erect test than during the supine test. Peak plasma insulin levels were also unaffected by posture, mean values being $173 \mu \mathrm{U} / \mathrm{ml}$ during supine tests and $184 \mu \mathrm{U} / \mathrm{ml}$ during the erect tests.

Postoperative.-Two operative procedures were used. Six patients had a procedure, either a Polya gastrectomy or a vagotomy plus antrectomy, which involved gastric resection. Their postoperative glucose tolerance tests are shown in Fig. 2. In contrast to the preoperative findings, posture had a considerable effect on the glucose tolerance, with a peak blood glucose much higher in the erect than in the supine position $(P<0.001)$. Nine patients had a vagotomy and pyloroplasty, and their postoperative glucose tolerance tests are shown in Fig. 3. In these patients the findings were similar and although the effects of the posture were less pronounced the peak glucose in the erect position was again significantly higher $(P<0.001)$ than in the supine position. In the supine position the degree of reactive hypo- 
glycaemia was $13 \mathrm{mg} / 100 \mathrm{ml}$ after a Billroth II procedure and $15 \mathrm{mg} / 100 \mathrm{ml}$ after vagotomy and pyloroplasty. In the erect position reactive hypoglycaemia was greater at $25 \mathrm{mg} / 100 \mathrm{ml}$ and $28 \mathrm{mg} / 100 \mathrm{ml}$ respectively, but this difference in the extent of hypoglycaemia in the two positions is not statistically significant. Peak plasma insulin levels reflected corresponding blood glucose values. When considering all these patients together, mean peak plasma insulins were higher at $197 \mu \mathrm{U} / \mathrm{ml}$ in the erect than in the supine position $(127 \mu \mathrm{U} / \mathrm{ml})$, but there was a wide scatter of results and the difference is not significant.

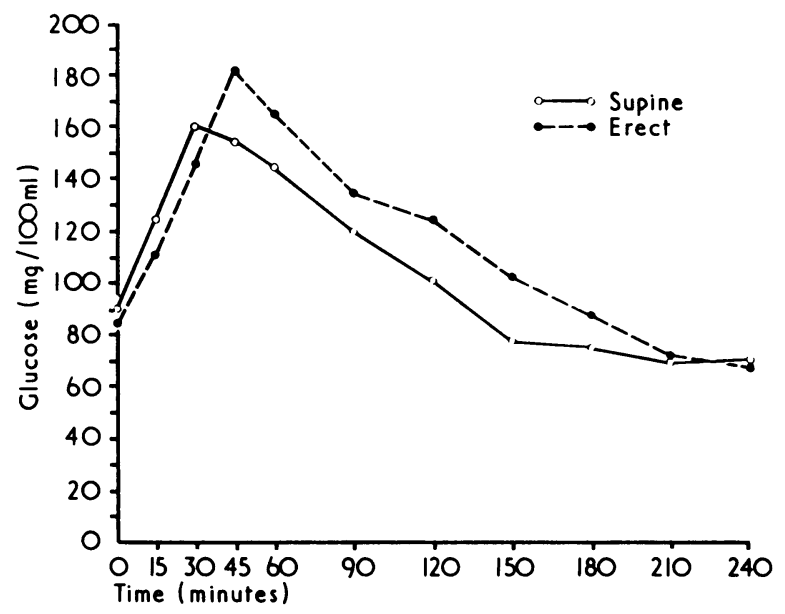

FIG. 1-Mean blood glucose levels after $50 \mathrm{~g}$ oral glucose in six patients with a duodenal ulcer.

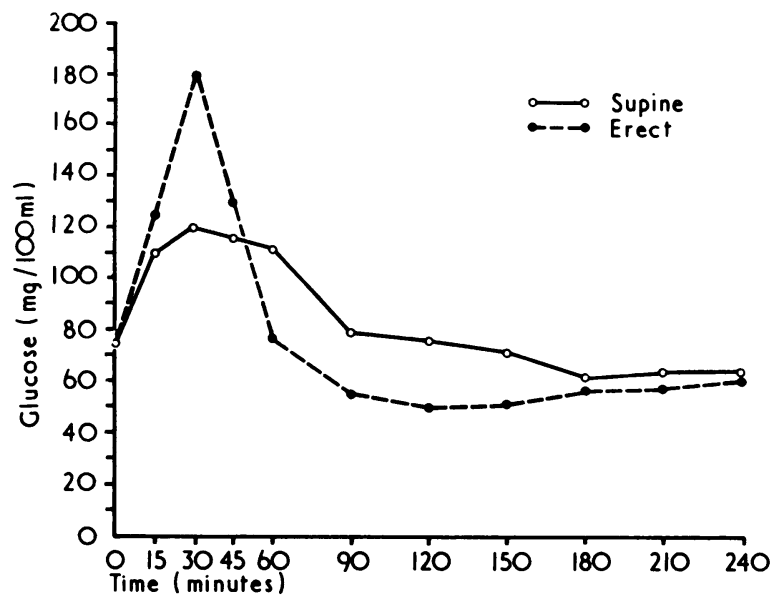

FIG. 2-Mean blood glucose levels after $50 \mathrm{~g}$ oral glucose in six patients after partial gastrectomy for duodenal ulcer.

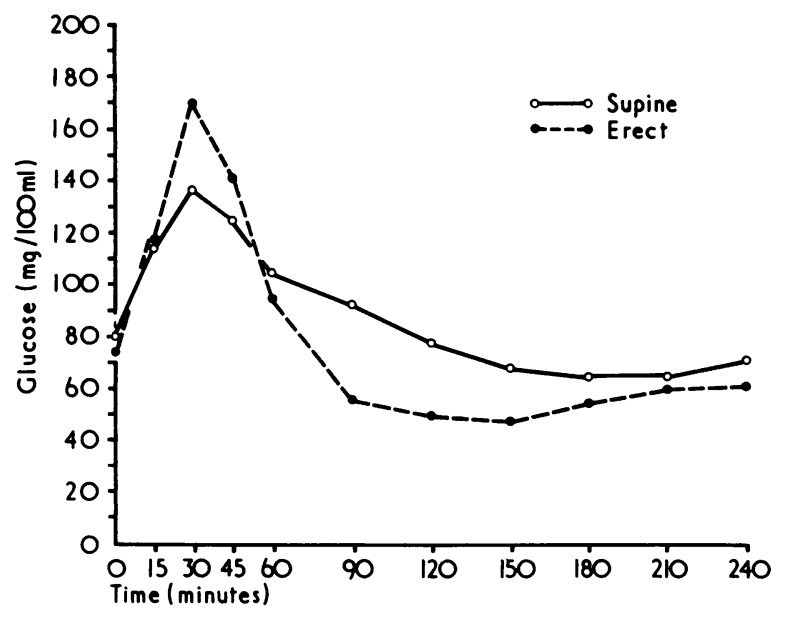

FIG. 3-Mean blood glucose levels after $50 \mathrm{~g}$ oral glucose in nine patients after vagotomy and pyloroplasty for duodenal ulcer.

\section{GASTRIC ULCER}

Preoperative.-Only four complete studies were performed. As in the duodenal ulcer patients, peak blood glucose values were a little higher in the erect than in the supine position (Fig. 4). Peak plasma insulin values were similar during the supine $(102 \mu \mathrm{U} / \mathrm{ml})$ and erect $(87.5 \mu \mathrm{U} / \mathrm{ml})$ studies.

Postoperative.-Only four complete studies were performed. Three of the patients had a Billroth I gastrectomy and two had a Polya gastrectomy. Posture did not effect glucose tolerance in these patients, their peak values and the mild reactive hypoglycaemia being similar (Fig. 5). Peak plasma insulin levels were slightly higher in the erect tests $(122 \mu \mathrm{U} / \mathrm{ml})$ than in the supine studies $(90.2 \mu \mathrm{U} / \mathrm{ml})$.

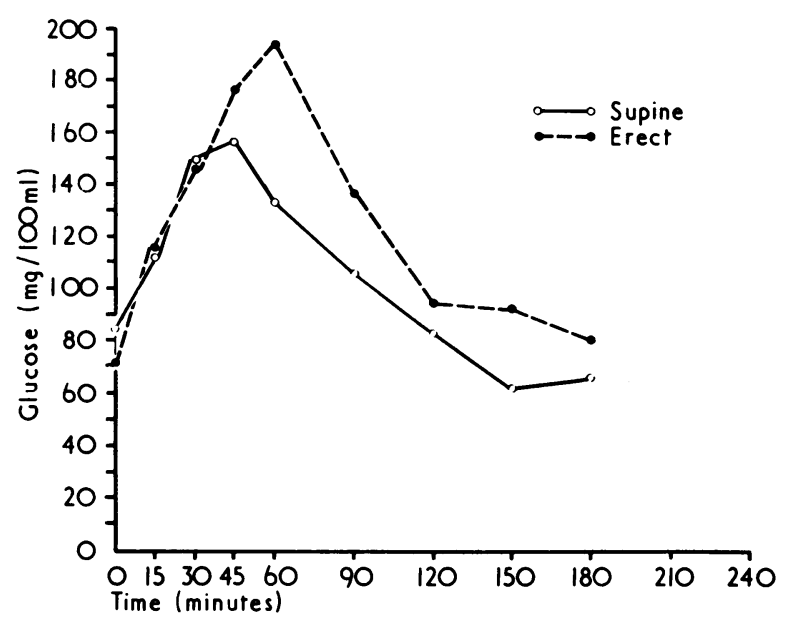

FIG. 4-Mean blood glucose levels after $50 \mathrm{~g}$ oral glucose in four patients with a gastric ulcer.

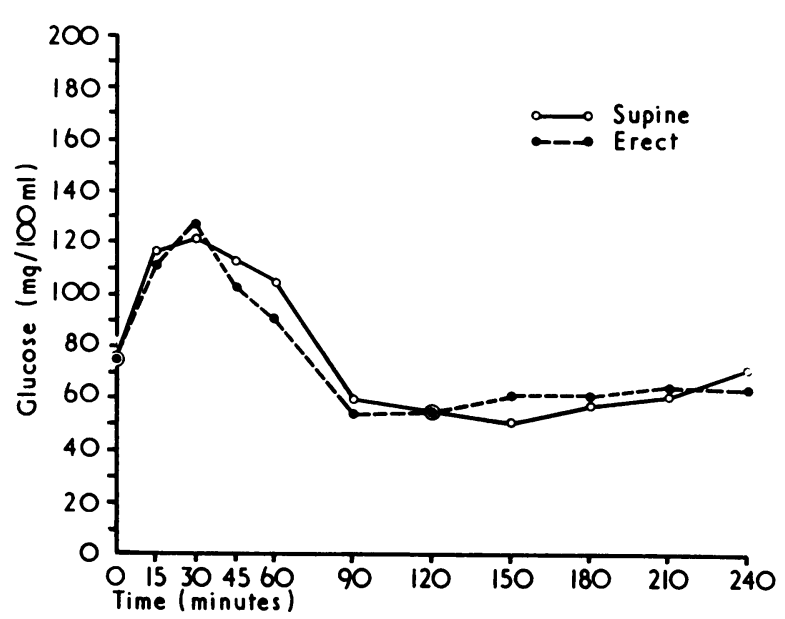

FIG. 5-Mean blood glucose levels after $50 \mathrm{~g}$ oral glucose in five patients after partial gastrectomy for gastric ulcer.

\section{Discussion}

The most striking feature of these studies is the noticeable effect of posture on glucose tolerance in patients after gastric surgery for duodenal ulcer. After either partial gastrectomy or vagotomy and pyloroplasty the peak blood glucose was significantly higher in the sitting patient than the supine patient. The extent of reactive hypoglycaemia was also greater in the erect position in these patients. In all studies the plasma insulins reflected the shape of the glucose tolerance curve. Preoperatively peak plasma insulin levels were unaffected by posture in both groups of patients. Postoperatively the plasma insulin was only changed in duodenal ulcer patients studied supine, in which position oral glucose tolerance curves were also flatter. 
It is likely that all the observed differences in glucose tolerance are due to changes in the rate of gastric emptying. Preliminary unpublished studies of our own indicate that after either Polya gastrectomy or vagotomy and pyloroplasty the emptying rate of a liquid glucose meal is much faster in the sitting than in the supine position.

After surgery for gastric ulcer neither peak blood glucose nor the degree of reactive hypoglycaemia was affected by posture. On inspection of individual results, in one of the two patients who had a Polya gastrectomy there was a postural change in glucose tolerance. Our unpublished studies of gastric emptying indicate that the absence of a postural effect on glucose tolerance in the group as a whole is due to the different type of gastrectomy (Billroth I), which is not associated with the rapid emptying seen after either the Polya procedure or vagotomy and pyloroplasty. This is consistent with other evidence that changes in the rate and pattern of gastric emptying after surgery are largely responsible for postgastrectomy reactive hypoglycaemia. In a previous paper suggesting this (Holdsworth et al, 1969) we did not specify the position of the patients during oral glucose tolerance tests. They were in fact supine, which probably explains the mild degree of reactive hypoglycaemia observed in the study. In numerous papers devoted to the study of postoperative glucose tolerance the position of the patient is likewise not stated, and may account for the variable frequency of reactive hypoglycaemia in different reports.

Abnormal glucose tolerance has from time to time been reported in patients with peptic ulcer, and it is possible that these, too, are caused by changed gastric emptying. Platt et al,
(1949) found higher peak blood glucose levels in duodenal ulcer patients after oral glucose than in controls, and although this was not confirmed by Buchanan et al. (1967) these workers found higher plasma insulin levels in duodenal ulcer subjects after oral glucose. Gastric emptying of a solid meal is faster in subjects with a duodenal ulcer than in normal subjects (Griffith et al. 1966) and if this is the case of oral glucose rapid gastric emptying could explain the reports of abnormal oral glucose tolerance curves in duodenal ulcer. In the present studies there are too few gastric ulcer subjects to make a valid comparison with the duodenal ulcer subjects, especially as no attempt was made to match them for age, sex, or weight.

We thank the patients for their co-operation, Professor I. \% McColl for permission to study them, and Professor J. Landon for $\vec{\circ}$ the plasma insulin determinations. The work was supported by research grants from the Joint Research Board of St. Bartholomew's Hospital, the North East Metropolitan Regional Hospital Board, and the United Sheffield Hospitals.

\section{References}

Buchanan, K. D., McKiddie, M. T., Lindsay, A. C., and Manderson, W. G. (1967). Gut, 8, 325 .

Griffith, G. H., Owen, G. M., Kirkman, S., and Shields, R. (1966). œ Lancet, 1, 1244.

Herbert, V., Lau, K. S., Gottlieb, C. W., and Bleicher, S. J. (1965). fournal of Clinical Endocrinology, 25, 1375

Holdsworth, C. D., Turner, D., and McIntyre, N. (1969). British Medical fournal, 4, 257.

McKelvey, S. T. D., Connell, A. M., and Kennedy, T. L. (1969). Gut,

Platt, W. D., jun., Dotti, L. B., and Beekman, R. S. (1949). Gastroenerology, 13, 20.

\title{
Head Injuries in Children
}

\author{
A. W. CRAFT, D. A. SHAW, N. E. F. CARTLIDGE
}

British Medical fournal, 1972, 4, 200-203

\section{Summary}

Two-hundred children with head injury admitted consecutively to paediatric wards in the two main hospitals in Newcastle upon Tyne have been studied. Eight children required neurosurgical operation. There were two deaths. Details of the cause and consequences of the accidents have been analysed and an attempt has been made to identify psychological or physical factors that may predispose to injury. There was a slightly higher proportion of children with what are regarded as adverse personality factors among the head injuries than in a control group and there were more left-handed children than would be expected in the general population. The results suggest that the modern "high-rise" bicycle may carry a special risk of head injury.

\section{Introduction}

Beyond the first year of life the main cause of death in children is accident. It has been estimated that one in 10 of the child population of the United Kingdom has a serious accident every Department of Neurology, Royal Victoria Infirmary, Newcastle upon
Pyne

A. W. CRAFT, M.B., B.S., Research Registrar

D. A. SHAW, M.B., F.R.C.P., Senior Lecturer

N. E. F. CARTLIDGE, M.B., M.R.C.P., First Assistant year, the annual total being greater than a million (Court and Jackson, 1972). Many accidents result in head injury, which is the principal cause of admission of children to hospital after trauma (Rickham, 1961). In the hospitals in Newcastle upon Tyne there has been a sixfold increase in the past 20 years in $\delta$ the numbers of children admitted with head injury (Fig. 1), and $₹$ in 1971 these accounted for $13.9 \%$ of all admissions to the 의 paediatric wards of the two major hospitals in the city. A number $N$ of factors in addition to the real rise in accident rate may have contributed to this increase, but its implications for the hospital service are obvious.

There have been several extensive surveys of head injury in $N$ childhood (Burkinshaw, 1960; Partington, 1960; Hendrick et al.,

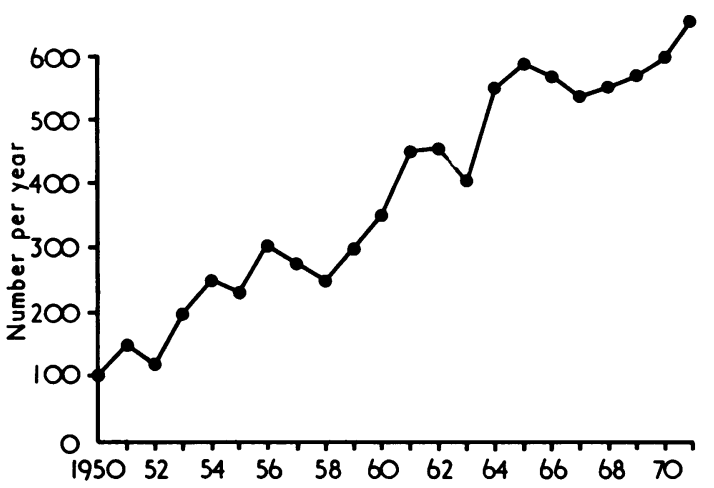

FG. 1-Paediatric head injury cases admitted to hospitals in Newcastle upon Tyne 1950-71. 